\title{
Quality maintenance of broccoli by the use of 1-MCP treatments
}

\section{TAMÁS ZSOM ${ }^{1 *}$, PETRA POLGÁRI ${ }^{1}$, LIEN PHUONG LE NGUYEN ${ }^{1,3}$, GÉZA HITKA ${ }^{1}$ and VIKTÓRIA ZSOM-MUHA ${ }^{2}$}

\author{
${ }^{1}$ Department of Postharvest Science and Sensory Evaluation, Szent István University, Faculty of Food \\ Science, Institute of Food Technology, Ménesi út 43-45, Budapest H-1118, Hungary \\ ${ }^{2}$ Department of Physics and Control, Szent István University, Faculty of Food Science, Institute of \\ Biosystems Engineering and Process Control, Somlói út 14-16, Budapest H-1118, Hungary \\ ${ }^{3}$ Institute of Biotechnology and Food Technology, Industrial University of Ho Chi Minh City, Vietnam
}

\section{CONFERENCE FULL PAPER}

Received: January 31, 2020 • Accepted: September 29, 2020

Published online: October 17, 2020

(C) 2020 The Author(s)

\begin{abstract}
Broccoli's high perishability and its sensitivity to negative quality changes (i.e., mass loss, ethylene induced degreening, abscission of leaves, and florets) generates quality problems during postharvest. Freshly harvested samples were stored at 5 and $21{ }^{\circ} \mathrm{C}$ after separately treated for $24 \mathrm{~h}$ with $625 \mathrm{ppb} 1$-methylcyclopropene (1-MCP), $24 \mathrm{~h}$ with $2 \mathrm{ppm}$ ethylene and 1-MCP followed by ethylene. Quality maintenance effectivity of 1-MCP was investigated during cold and room storage by non-destructive optical methods (chlorophyll fluorescence and DA-index ${ }^{\mathbb{B}}$ ) and by the evaluation of the visual physiological symptoms. The highly positive effects of 1-MCP treatment combined with cold storage were obviously proven on quality maintenance providing better retention of initial quality related to the initial mature green stage as chlorophyll content related DA-index ${ }^{\circledR} ; F_{m}, F_{v}, F_{v} / F_{m}$, and $F_{m} / F_{0}$ chlorophyll fluorescence values. From the practical point of view, the rapid, and easy-to-use Sintéleia FRM01-F Vis/NIR DA-meter ${ }^{\circledR}$ could be applied relatively easy for the quality measurement of broccoli. The reproducibility of quality determination could be increased by the enhanced number of measuring points or using computer aided imaging methods (i.e., chlorophyll fluorescence imaging, machine vision system) providing global and more reliable information about quality changes.
\end{abstract}

\footnotetext{
*Corresponding author. Email: Zsom.Tamas@szie.hu
} 


\section{KEYWORDS}

chlorophyll, degradation, fluorescence, DA-index ${ }^{\circledR}, 1$-methyl-cyclopropene, ethylene, degreening

\section{INTRODUCTION}

Nowadays, postharvest quality issues of fresh horticultural products are continuously under the scope of interest. During the postharvest life of horticultural products, especially during cold storage, or even during ambient storage or refrigerated shelf-life, several type of losses/injury/ damage occurs: chilling injury (Cen et al., 2016; Patel et al., 2016; Zsom et al., 2018); ethylene damage (Martinez-Romero et al., 2007; Watkins \& Nock, 2012); mechanical injury (Li \& Thomas, 2014); low $\mathrm{O}_{2}$ and/or high $\mathrm{CO}_{2}$ (Beaudry, 1999). Among vegetables, broccoli is one of the favorites of the cabbage family. Broccoli is a highly perishable vegetable. According to Cantwell and Suslow (1997), low temperature is extremely important to achieve the adequate shelf-life. Optimal temperature of $0{ }^{\circ} \mathrm{C}$ with $>95 \%$ relative humidity $(\mathrm{RH})$ is required to optimize broccoli storage life (21-28 days). Heads stored at $5{ }^{\circ} \mathrm{C}$ can offer a shorter storage life for a maximum of 10-14 days; but its storage life at $10{ }^{\circ} \mathrm{C}$ is only about 5 days. Ethylene can easily diffuse into and out of plant tissues from endogenous (biological) and exogenous (non-biological) sources (Saltveit, 1999). Additionally, broccoli is extremely sensitive upon exposure to ethylene from natural origin (produced by climacteric fruits) or artificial origin (i.e., from exhaust fumes of internal combustion engines). Due to ethylene exposure, yellowing (chlorophyll degradation) and abscission of the florets and leaves are the most common postharvest symptoms. Exposure to 2 ppm ethylene at $10{ }^{\circ} \mathrm{C}$ reduces the possible shelf-life by $50 \%$ (Cantwell \& Suslow, 1997). Additionally, broccoli is also really sensitive to mechanical injury; high mass loss caused softening, mold development and decay among improper transportation and retail conditions. In order to avoid such losses, individual shrink packaging (film wrapping) is the commonly used procedure. Novel postharvest technologies (i.e., the use of ethylene binding packaging materials, or ethylene scavenging agents) could serve effectively for these purposes. 1-MCP (1-methyl-cyclopropene) application as a novel postharvest treatment (Blankenship \& Dole, 2003) is proved to be effective against undesired postharvest ripening of several fruits such as apples, bananas, pears, plums, melons (Bagnato et al., 2003; Nguyen et al., 2016; Nguyen et al., 2018; Watkins, 2006), but the possible application for vegetables, especially for broccoli is rather rare lately (Fan \& Mattheis, 2000; Fernández-Léon et al., 2013; Sabir, 2012; Toivonen \& DeEll, 1998; Yuan et al., 2010). The main effect of 1-MCP is that this highly active and harmless compound is able to fit in, bind more strongly and block the ethylene receptors than ethylene, thus prolonging storage life (especially if used parallel to cold and/or controlled atmosphere storage), preventing ethylene-dependent physiological responses and providing better retail quality. According to Zsom-Muha and Felföldi (2007), the postharvest quality assessment and control is rightly waiting for the new possibilities of reliable, objective, and quantitative methods. These novel methods are also welcomed for broccoli quality determination because of its special morphology and structure derived measuring difficulties. So, the now available novel non-destructive optical measuring methods are based for example on the measurement of chlorophyll content related absorbance differences, chlorophyll fluorescence characteristics, or carried out by machine vision or hyperspectral imaging systems offering the possibility to non-invasively characterize the quality changes of perishable fruits and vegetables (Gorbe \& Calatayud, 2012; Ziosi, 2008; Pinto et al., 2015). 
The aim of our research was to evaluate and prove the possible positive effects of 1-MCP treatment on keeping the quality of fresh broccoli at cold and simulated shelf-life storage temperatures by non-destructive measuring methods. Additionally, the applicability of possible non-invasive measuring methods for broccoli quality changes was investigated.

\section{MATERIALS AND METHODS}

Fresh mature green broccoli samples (Brassica oleraceae $c v$. botrytis var. italica) were obtained from an experienced broccoli grower in uniform maturity within $12 \mathrm{~h}$ after harvest. According to uniformity, 30 broccolis were selected and randomly divided into four groups according to further treatments. Broccolis were stored in temperature controlled refrigerators at $5 \pm 0.5{ }^{\circ} \mathrm{C}$ for 9 days. In case of ambient temperature of $21 \pm 0.5{ }^{\circ} \mathrm{C}$, samples were stored only for 5 days due to the fast quality degradation. Broccoli samples were wrapped in commercially available Low-density polyethylene (LDPE) bags. Fifteen equally distributed individual measuring points were selected on the head (or curd, which consists of many floral shoots) of each broccoli sample. These fifteen points were randomly selected for non-destructive chlorophyll fluorescence analysis and for DA-index ${ }^{\circledR}$ evaluation.

In three different series, the following treatments were carried out. Four-four pieces of fresh broccolis per storage temperatures were treated for $24 \mathrm{~h}$ with 1-MCP (625 ppb gaseous 1-MCP concentration, released from a tablet form in distilled water according to the SmartFresh ${ }^{\mathrm{SM}}$ system application requirements), $2 \mathrm{ppm}$ of ethylene $\left(\mathrm{C}_{2} \mathrm{H}_{4}\right)$ and the consecutive combination of the earlier two (24 h of 1-MCP followed by $24 \mathrm{~h}$ of ethylene) in an air-tight plastic cabinet equipped with a small electric fan for adequate air distribution inside the cabinet, respectively.

Mass loss (\% of fresh mass) was calculated based on the measured mass data using a digital laboratory balance for each sample on every measuring day.

Broccoli overall quality, maturity, and color related photosynthetically active chlorophyll content changes - referring to the photosynthetic activity, integrity, and efficiency of photosystem II (PSII) - were characterized by the measurement of chlorophyll fluorescence parameters. $F_{0}$ (dark fluorescence signal), $F_{m}$ (maximum dark fluorescence signal), and $F_{v}$ (variable fluorescence $F_{v}=F_{m}-F_{0}$ ) parameters at the above mentioned points of each broccoli were measured by a PAM WinControl-3 controlled MONI-PAM multi-channel chlorophyll fluorometer (Heinz Walz GmbH, Germany). The calculated index of $F_{v} / F_{m}$ reflects the potential maximum photon yield of photochemistry, i.e., the maximum photochemical efficiency. It is a valuable tool to determine both photosynthetic capacity, stability and follow the maturity related chlorophyll degradation. Additionally, the ratio, $F_{m} / F_{0}$ was also calculated.

In order to characterize the change in surface color or tissue related chlorophyll content in the heads of the broccolis, the DA (or $\Delta \mathrm{A}$ ) index ${ }^{\circledR}$ was measured by a FRM01-F type Vis/NIR DA-meter ${ }^{\circledR}$ (Sintéleia s.r.l., Italy) at every individually and randomly selected 15 measurement points on the head of the samples, as it was mentioned earlier. This non-destructive maturity index (also named as index of absorbance difference, $I_{A D}$ ) created by Costa and co-workers (Ziosi et al., 2008) is calculated based on the difference in absorbance between the wavelengths of 670 and $720 \mathrm{~nm}$ near the chlorophyll-a absorption peak. The value of it is proportional to the amount of chlorophyll present in the fruit, and varies from 0 to 5 . 
Overall visual quality information about the effects of the treatments, digital images were taken by an Olympus SP-350 digital camera $(3,264 \times 2,448$ pixels of resolution, Olympus Corporation, Japan) mounted on a vertical stand in a photo-box.

Data were converted by means of routines in MS-Excel and were analyzed using the SPSS for Windows ver. 14. Results are presented in figures with mean and bars represent confidence interval (CI) for mean (95\% CI). Statistical analysis was performed at $95 \%$ significance level $(\alpha=0.05)$.

\section{RESULTS AND DISCUSSION}

Based on mass loss data of the treatments, significant difference was found between the cold $\left(5{ }^{\circ} \mathrm{C}\right)$ and ambient temperature $\left(21^{\circ} \mathrm{C}\right)$ stored samples from day 4 , clearly proving the positive effect of reduced temperature on mass loss and quality retention (Fig. 1). No significant difference could be observed at $5{ }^{\circ} \mathrm{C}$ between the 1-MCP-treated and the 1-MCP + $\mathrm{C}_{2} \mathrm{H}_{4}$-treated samples throughout the whole storage period. This revealed the extremely positive effect of 1-MCP due to its much higher affinity to fit in and bind to active ethylene receptors than ethylene, providing less possibility for ethylene to cause leaf abscission and increased respiration related mass loss and quality degradation. The highest mass loss was observed in case of ethylene treated and control samples stored at $21{ }^{\circ} \mathrm{C}$ due to the additive negative effect of higher temperature and ethylene caused excessive floret and leaf abscission (especially from the 4th day). The lowest mass loss was observed in case of 1-MCP-treated samples together with the best preservation of initial mature green color. Remarkably, control samples may have been slightly exposed to ethylene due to the impossibility of full hermetically separate samples from ethylene. From day 5, in case of 1-MCP-treated samples stored at $21{ }^{\circ} \mathrm{C}$, a slight yellowish-brownish discoloration of the heads could be observed, but with lower intensity of floret abscission. Contrary to this, ethylene treated samples were almost unable to measure due to the massive floret abscission of the head resulted in the excessive loss of the selected measurement points. Additionally, together with the beginning of mold development on the heads, these changes caused a bad overall broccoli head quality. All the above and later mentioned changes were clearly supported by the digital pictures taken (Fig. 2).

Fresh broccoli's original mature green color is one of its main quality features. According to our results, the photosynthetically active chlorophyll content related parameters showed also, the positive effect of cold temperature $\left(5^{\circ} \mathrm{C}\right)$ combined with 1 -MCP treatments (Figs. 3 and 4 ) providing the preservation of green color. Having compared the two temperature treatments, in case of minimal $\left(F_{0}\right)$ fluorescence (data not shown) clear and significant difference was found between the 1-MCP-treated sample and the only ethylene treated samples and untreated control samples. In case of $21{ }^{\circ} \mathrm{C}$ stored samples the positive effect of 1-MCP is kept the samples until the 3rd day, but it was followed by a rapid decrease. In case of control and ethylene treated samples, this steep and rapid decrease occurred right after the 1st day as negative quality change and rapid degreening of the florets.

The same characteristic change was observed in case of maximal $\left(F_{m}\right)$, variable $\left(F_{v}\right)$ fluorescence values (data not shown), and additionally in case of $F_{v} / F_{m}$ and $F_{m} / F_{0}$ values (Figs. 3 and 4). Furthermore, these later parameters show more clearly the significant and 


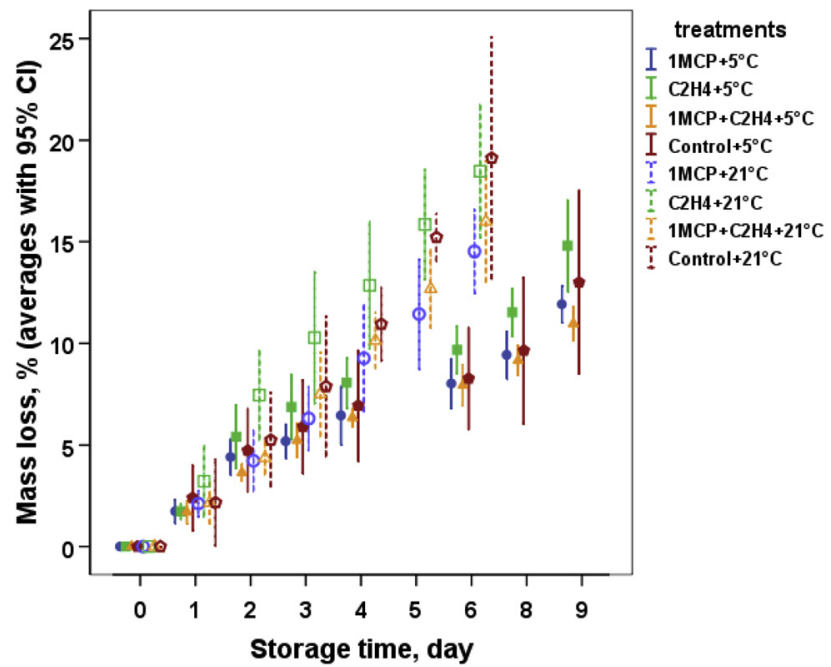

Fig. 1. Change of average mass loss of the broccoli samples at $5{ }^{\circ} \mathrm{C}$ cold and at $21{ }^{\circ} \mathrm{C}$ storage

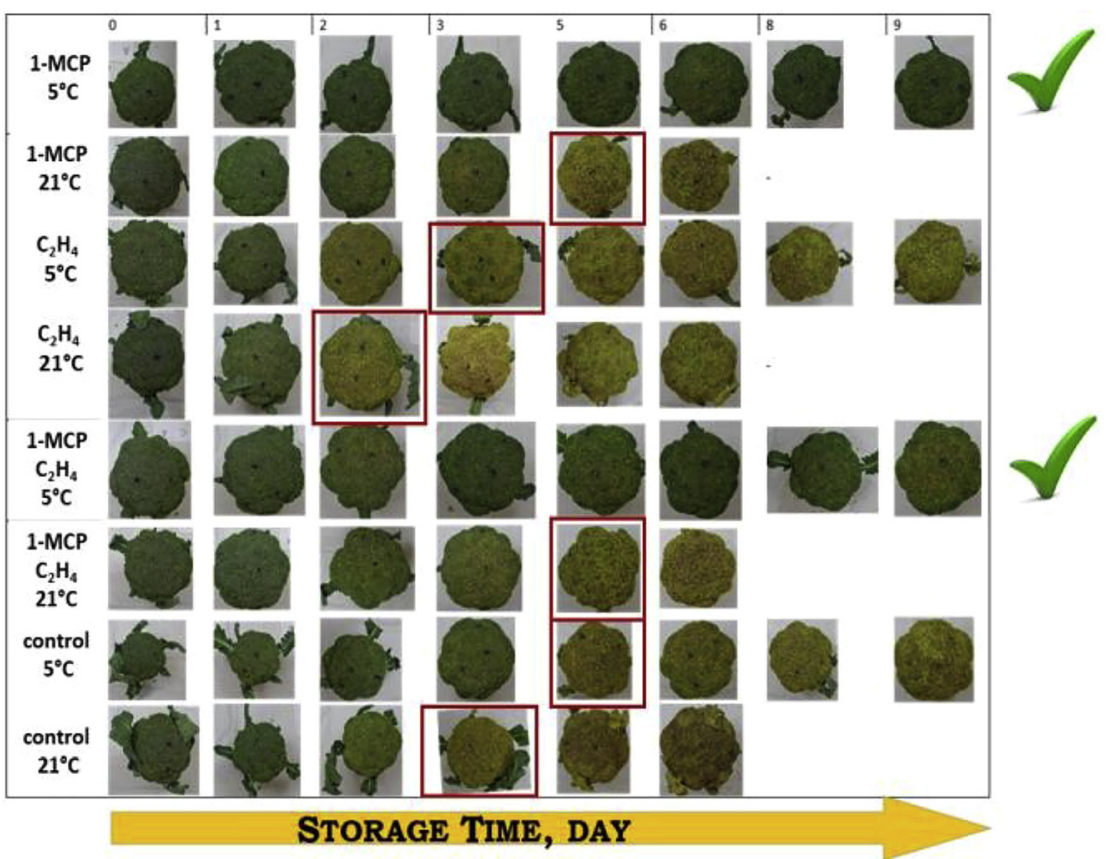

Fig. 2. Overall broccoli quality changes represented by the digital pictures taken during storage 

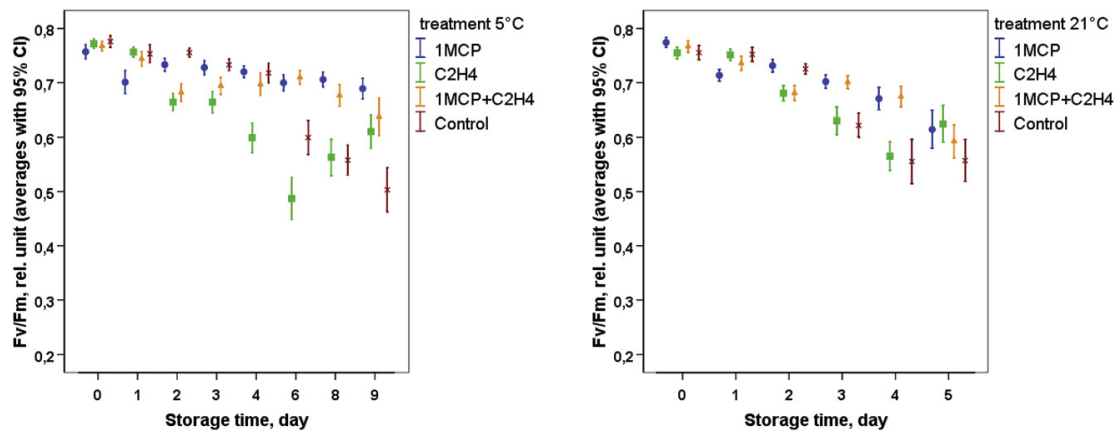

Fig. 3. The $F_{v} / F_{m}$ chlorophyll fluorescence change of broccoli samples stored at $5{ }^{\circ} \mathrm{C}$ (left) and at room temperature of $21^{\circ} \mathrm{C}$ (right).
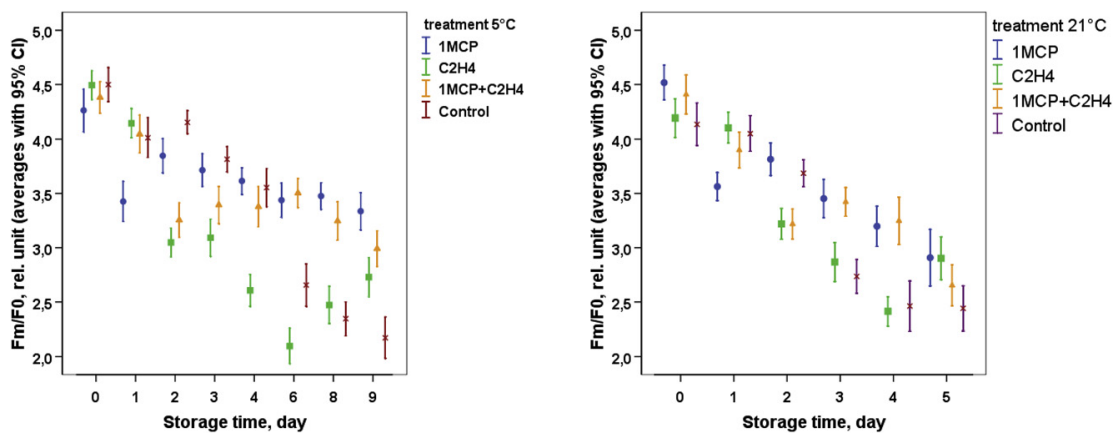

Fig. 4. The $F_{m} / F_{0}$ ratio's change of broccoli samples stored at $5{ }^{\circ} \mathrm{C}$ (left) and at $21{ }^{\circ} \mathrm{C}$ (right).

positive effect of low temperature and 1-MCP-treatment on photosynthetically active chlorophyll related green color retention (Figs. 3 and 4). It was observed that the rapid degreening related decrease of control and ethylene treated samples was associated with the fluorescence parameters' steep decrease from the 2 nd and 4 th day in case of 21 and $5{ }^{\circ} \mathrm{C}$, respectively (Figs. 3 and 4 ). These changes are also to be followed in the digital pictures taken (see Fig. 2).

The 1-MCP-treated samples stored at $5{ }^{\circ} \mathrm{C}$ retained higher photosynthetic activity during the entire storage period. The average initial $F_{v} / F_{m}$ fluorescence values $(>0.7)$ represented the mature green and highly photosynthetically active chlorophyll containing intact broccoli tissue (Fig. 3). The less significant change of $F_{0}$ revealed that this parameter was found to be a less sensible parameter than the $F_{m}, F_{v}, F_{v} / F_{m}$ or $F_{m} / F_{0}$ (see Figs. 3 and 4 ).

The data revealed that they characterize more reliably and sensibly the ethylene induced degreening related chlorophyll fluorescence changes and the 1-MCP provided green color (quality) preservation/retention, especially during cold storage at $5{ }^{\circ} \mathrm{C}$. 

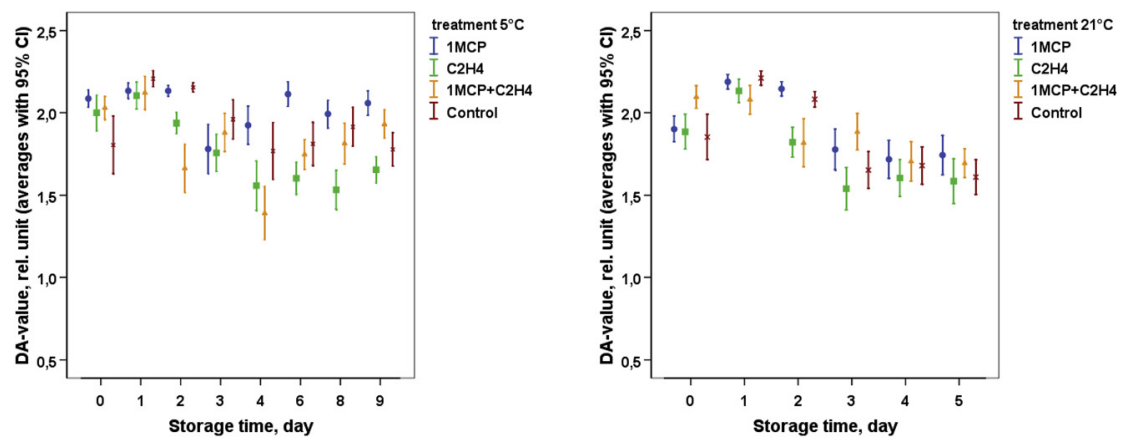

Fig. 5. The Change of broccoli's DA index ${ }^{\circledR}$ during storage at $5{ }^{\circ} \mathrm{C}$ (left) and at $21{ }^{\circ} \mathrm{C}$ (right)

The DA-index ${ }^{\circledR}$ values of the treatments also showed clearly (notice the different horizontal scaling of Fig. 5) the earlier mentioned significant difference between the two temperature treatments and the 1-MCP or ethylene treatments, respectively. This temperature dependent, rapid and steep decrease in DA-index ${ }^{\circledR}$ values of at $21^{\circ} \mathrm{C}$ stored samples clearly started from day 2 (Fig. 5, right) due to the negative effect of higher temperature and ethylene, compared to the less moderate change observed at $5{ }^{\circ} \mathrm{C}$ (Fig. 5 left) started later only about the $4-5$ th day provided by the 1-MCP.

Our results coincidence with the results of Fan and Mattheis (2000), Fernández-León et al. (2013), Sabir (2012), and Yuan et al. (2010) suggesting the application of combined treatments with 1-MCP and low temperature cold storage for quality maintenance of fresh broccoli.

\section{CONCLUSIONS}

The effects of 1-MCP, ethylene and 1-MCP followed by ethylene treatments on fresh, mature green broccoli samples' quality were investigated by non-destructive optical methods during the 5 and 9 days long storage at 5 and $21{ }^{\circ} \mathrm{C}$, respectively. The temperature and treatment dependent changes in overall and keeping quality, mass loss, photosynthetically active chlorophyll content related characteristics (represented well by $F_{m}, F_{v}, F_{v} / F_{m}, F_{m} / F_{0}$, and DAindex ${ }^{\circledR}$ ) were found to characterize reliably the highly positive effect of 1-MCP treatment on fresh mature green broccoli applied within $12 \mathrm{~h}$ after harvest. From our experiment, it is clearly to be seen that the quality preserving combined effect of 1-MCP and cold storage together was proven to prevent or at least minimize the highly deteriorative effect of gaseous ethylene (increased mass loss, chlorophyll breakdown caused yellowing, leaf, and florets abscission). Even the $24 \mathrm{~h}$ long $2 \mathrm{ppm}$ ethylene treatment was not able to eliminate the effect of 1-MCP treatment ( $24 \mathrm{~h}, 625 \mathrm{ppb})$ due to the complete and effective blockage of ethylene receptors during the 9 days period of cold storage at $5{ }^{\circ} \mathrm{C}$. Consequently, the application of combined 1-MCP and low temperature cold storage treatments could be suitable for longer postharvest quality maintenance of fresh broccoli. Concerning reproducibility of the applied 
measurements for broccoli quality determination, the increased number of measuring points or the use of computer aided imaging methods (i.e., chlorophyll fluorescence imaging, machine vision system) providing global and more reliable information related to quality changes could serve more reliable data.

\section{ACKNOWLEDGEMENTS}

The Project was supported by the European Union and co-financed by the European Social Fund (grant agreement no. EFOP-3.6.3-VEKOP-16-2017-00005); and by the Ministry for Innovation and Technology within the framework of the Higher Education Institutional Excellence Program (NKFIH-1159-6/2019) in the scope of plant breeding and plant protection researches of Szent István University. 1-MCP treatment, as an application of SmartFresh ${ }^{\mathrm{SM}}$ Quality System, was provided by AgroFresh (Philadelphia, USA).

\section{REFERENCES}

Bagnato, N., Barrett, R., Sedgley, M., and Klieber, A. (2003). The effects on the quality of Cavendish bananas, which have been treated with ethylene, of exposure to 1-methylcyclopropene. International Journal of Food Science \& Technology, 38: 745-750.

Beaudry, R.M. (1999). Effect of $\mathrm{O}_{2}$ and $\mathrm{CO}_{2}$ partial pressure on selected phenomena affecting fruit and vegetable quality. Postharvest Biology and Technology, 15(3): 293-303, https://doi.org/10.1016/S09255214(98)00092-1.

Blankenship, S.M. and Dole, J.M. (2003). 1-methylcyclopropene: a review. Postharvest Biology and Technology, 28: 1-25.

Cantwell, M. and Suslow, T. (1997). Broccoli - Recommendations for Maintaining Postharvest Quality. Broccoli Produce Facts - University of California, Davis, Postharvest Technology Center. Perishables Handling \#92, http://postharvest.ucdavis.edu/files/259443.pdf.

Cen, H., Lu, R., Zhud, Q., and Mendoza, F. (2016). Nondestructive detection of chilling injury in cucumber fruit using hyperspectral imaging with feature selection and supervised classification. Postharvest Biology and Technology, 111:352-361.

Fan, X. and Mattheis, J. P. (2000). Yellowing of broccoli in storage is reduced by 1-methylcyclopropene. HortScience, 35(5): 885-887.

Fernández-León, M.F., Fernández-León, A.M, Lozano, M., Ayuso, M.C., and González-Gómez, D. (2013). Different postharvest strategies to preserve broccoli quality during storage and shelf life: controlled atmosphere and 1-MCP. Food Chemistry, 138(1): 564-573.

Gorbe, E. and Calatayud, A. (2012). Applications of chlorophyll fluorescence imaging technique in horticultural research: a review. Scientia Horticulturae, 38: 24-35.

Li, Z. and Thomas, C. (2014). Quantitative evaluation of mechanical damage to fresh fruits (a review). Trends in Food Science \& Technology, 35(2): 138-150, https://doi.org/10.1016/j.tifs.2013.12.001.

Martínez-Romero, D., Bailén, G., Serrano, M., Guillén, F.,Valverde, J.M., Zapata, P., Castillo, S., and Valero, D. (2007). Tools to maintain postharvest fruit and vegetable quality through the inhibition of ethylene 
action: a review. Critical Reviews in Food Science and Nutrition, 47(6): 543-560, https://doi.org/10.1080/ 10408390600846390.

Nguyen, L.P.L., Hitka, G., Zsom, T., and Kókai, Z. (2016). Application of 1-MCP on apricots at different temperatures and days after harvest. Acta Alimentaria, 45(4): 542-550.

Nguyen, L.P.L., Horváth, V., Dam, M.S., Hitka, G., Zsom, T., and Kókai, Z. (2018). Effect of 1-MCP, ethylene absorber and ozone on melon quality during storage. Progress in Agricultural Engineering Sciences, 14(s1): 101-110, https://akademiai.com/doi/abs/10.1556/446.14.2018.S1.10.

Patel, B., Tandel, Y.N., Patel, A.H., and Patel, B.L. (2016). Chilling injury in tropical and subtropical fruits: a cold storage problem and its remedies: a review. International Journal of Science, Environment and Technology, 5(4): 1882-1887.

Pinto, C., Reginato, G., Shinya, P., Mesa, K., Díaz, M., Atenas, C., and Infante, R. (2015). Skin color and chlorophyll absorbance: Indices for establishing a harvest date on non-melting peach. Scientia Horticulturae, 192: 231-236.

Sabir, F.K. (2012). Postharvest quality response of broccoli florets to combined application of 1-methylcyclopropene and modified atmosphere packaging. Agricultural and Food Science, 21: 421-429.

Saltveit, M.E. (1999). Effect of ethylene on quality of fresh fruits and vegetables. Postharvest Biology and Technology, 15: 279-292.

Toivonen, P. M. and DeEll, J. R. (1998). Differences in chlorophyll fluorescence and chlorophyll content of broccoli associated with maturity and sampling section. Postharvest Biology and Technology, 14: 61-64.

Yuan, G., Sun, B., Yuan, J., and Wang, Q. (2010). Effect of 1-methylcyclopropene on shelf life, visual quality, antioxidant enzymes and health-promoting compounds in broccoli florets. Food Chemistry, 118(3): 774-781.

Watkins, C.B. (2006). The use of 1-methylcyclopropene (1-MCP) on fruits and vegetables. Biotechnology Advances, 24(4): 389-409.

Watkins, C.B. and Nock, J.F. (2012). 2012 production guide for storage of organic fruits and vegetables. NYS IPM Publication No. 10, pp. 1-67, http://hdl.handle.net/1813/42885.

Ziosi, V., Noferini, M., Fiori, G., Tadiello, A., Trainotti, L., Casadoro, G., and Costa, G. (2008). A new index based on vis spectroscopy to characterize the progression of ripening in peach fruit. Postharvest Biology and Technology, 49(3): 319-329.

Zsom-Muha, V. and Felföldi, J. (2007). Vibration behaviour of long shape vegetables. Progress in Agricultural Engineering Sciences, 3(1): 21-46.

Zsom, T., Strohmayer, E., Nguyen, L.P.L., Hitka, G., and Zsom-Muha, V. (2018). Chilling injury investigation by non-destructive measuring methods during banana cold storage. Progress in Agricultural Engineering Sciences, 14(s1), 147-158, https://akademiai.com/doi/abs/10.1556/446.14.2018.S1.14.

Open Access. This is an open-access article distributed under the terms of the Creative Commons Attribution 4.0 International License (https://creativecommons.org/licenses/by/4.0/), which permits unrestricted use, distribution, and reproduction in any medium, provided the original author and source are credited, a link to the CC License is provided, and changes - if any - are indicated. (SID_1) 